\title{
International Journal of Advanced Multidisciplinary Research
}

ISSN: 2393-8870

www.ijarm.com

DOI: 10.22192/ijamr

Volume 3, Issue 10 -2016

Research Article

DOI: http://dx.doi.org/10.22192/ijamr.2016.03.10.008

\section{Effectiveness of social skill training on social skills among first year Baccalaureate Nursing students}

\author{
J.Anitha* and Dr.C.Susila** \\ *Assistant Professor, Indira College of Nursing, Thiruvallur, Tamilnadu, India \\ *** Principal, Billroth College of Nursing, Chennai, Tamilnadu, India \\ *Corresponding Author: anitajayaraj@yahoo.co.in
}

Keywords

Social Skill Training,

Social Skills,

Nursing students.

\section{Abstract}

Nurses are a vital personality in health care setting. Nurses as interdisciplinary team member interacts with patients, families, communities, and the society they practice in. The main objective of the study was to determine the effectiveness of social skill training among first year baccalaureate nursing students. The participants were first year nursing students $(\mathrm{N}=50)$. Pre experimental, one group pre test post test design was used for the study. Social skill checklist was administered. Social skill training (SST) was given for about 8 sessions for 6 weeks. The results revealed SST has significantly influenced the social skills of the nursing students. The major findings of the study revealed that the overall mean improvement in level of social skills. Pretest the overall mean value of level of social skill was 6.58 , in posttest the overall mean value level of social skill was 17.9.

\section{Introduction}

Humans are born without any culture. The individual get transformed by our family, teachers and from the environment into a cultural and socially adaptable individual that's why man is called social animal. Social skills are a skill facilitating interaction and communication with others. Social rules and relations are created, communicated and changed in verbal and non-verbal ways. This process of learning such skills is called socialization.

Social skills are the behaviors, verbal and non-verbal, that we use in order to communicate effectively with other people. Social skills are governed by culture, beliefs and attitudes. They continuously change and develop throughout our lives. A person when uses social skills to effectively interact with friends, family, workmates and strangers is said to have social competence. Some examples of social skills are:
Eye contact with others during conversation, Smiling when greeting people, Shaking hands when meeting someone, Using the right tone and volume of voice, expressing opinions to others, Perceiving how others are feeling and showing empathy and appropriate emotional responses.

The list of social skills goes on and on. Many of us do not even realize that these are skills but treat them as part of everyday life. Unfortunately, for some people socializing is not that easy, perhaps because they lack social skills or do not feel comfortable using their social skills. Building social skills is not something we're magically born with - it's something that is learned from childhood interaction with families, friends, and others while growing up. If you develop just good social skills the student can become a star nurse! 


\section{Need for the Study}

Nurses as a good listener, manager and skilled professional are desperate in need of good social skills like

- Excellent people skills

- Good communication and observation

- Ability to answer questions and offers advice

- Dealing with emotionally charged situations are some of the essential qualities for a nurse.

Appropriate use of Social skills in turn, improve passion, Good work ethics, Good inter personal relationship, think on the feet and make good decisions so that He/she can fit into the unit's structure and culture. In the effort to develop strong and economical tools for nursing students, clinical communication and social communication, the investigator insists every Nursing student has to enhance their social skills. In the present study, social skills training (SST) intervention for nurses was focused on basic social skills and interactive social skill.

\section{Statement of the problem}

A pre experimental study to assess the effectiveness of social skill training on social skills among first year Baccalaureate Nursing students at Billroth college of Nursing, Chennai.

\section{Objectives of the study}

- To assess the pre test level of social skills.

- To assess the effectiveness of social skill training.

- To assess the post level of social skills.

- To associate the selected demographic variables with level of social skill.

\section{Research Methodology}

A pre experimental design was adopted for this study. The sample size was 50 . The samples selected were first year baccalaureate nursing students. A modified checklist was developed by adopting Arnold P. Goldstein et al social skill checklist ${ }^{4}$ and assed the level of social skills among the students. The tool was validated by experts and found to be valid for this study. The reliability was established through testretest method. The Karl Pearson coefficient of correlation was computed and the reliability was found $r=0.9$. The main study was conducted for a period of 6 week s after obtaining the formal consent from the principal of college of nursing. Totally 50 samples were selected by purposive sampling technique. Oral and written consent was obtained from the participants. After brief introduction about the study pre test was done using the social skills checklist. The important interactive social skills included in training were 1. Starting a Conversation with new or unfamiliar Person, 2. Maintaining Conversations by Asking Questions, 3. Ending Conversations 4. Refusing requests, 5. Asking for Help 6. Making Apologies were trained to them by role-play and Basic social skills included in the training were 1 . Listening to others, 2. Making request, 3. Expressing positive feelings, 4. Expressing unpleasant feelings were taught by group counseling. Group counseling was conducted for about $30 \mathrm{~min}$ in a session. Role-play was done for about fifteen minutes in a session. About 8 sessions were conducted. The post test was conducted after the completion of sessions by using the same checklist. Descriptive and inferential statistics were used to analyze the findings of the study.

\section{Results and Discussion}

The findings of the present study revealed that 27 (54\%) of the students were in the age group of 18 $20 \mathrm{yrs}$ and the minimum of $23(46 \%)$ students are in age group 17-18yrs. And the majority of gender was female $44(88 \%)$ than male $6(12 \%)$.The students Higher secondary medium of education is English was 29(58\%), and 21(42\%) students were from Tamil medium. Regarding the type of family $45(90 \%)$ are from nuclear family and 5(10\%) of them are from joint family. In the type of stay $43(86 \%)$ are staying in hostel, 7 (14\%) are day scholars. Regarding parents highest educational qualification, $9(18 \%)$, of them were illiterate, 24 (48\%) had SSLC qualification, 12 (24\%) had HSE qualification, $5(10 \%)$ had degree qualification. In the Habitual 24(48\%) were from urban, 26(52\%) were from rural area. 
Int. J. Adv. Multidiscip. Res. (2016). 3(10): 78-81

Table -1 Frequency and percentage distribution of pretest and posttest level of social skills among first year students.

\begin{tabular}{|c|c|c|c|c|}
\hline \multirow{2}{*}{ Level of social skill } & \multicolumn{2}{|c|}{ Pre test } & \multicolumn{2}{c|}{ Post test } \\
\cline { 2 - 5 } & No & No & \% \\
\hline Poor social skills & 24 & $48 \%$ & 7 & $14 \%$ \\
\hline Average social skills & 16 & $32 \%$ & 17 & $34 \%$ \\
\hline Good social skills & 10 & $20 \%$ & 26 & $52 \%$ \\
\hline
\end{tabular}

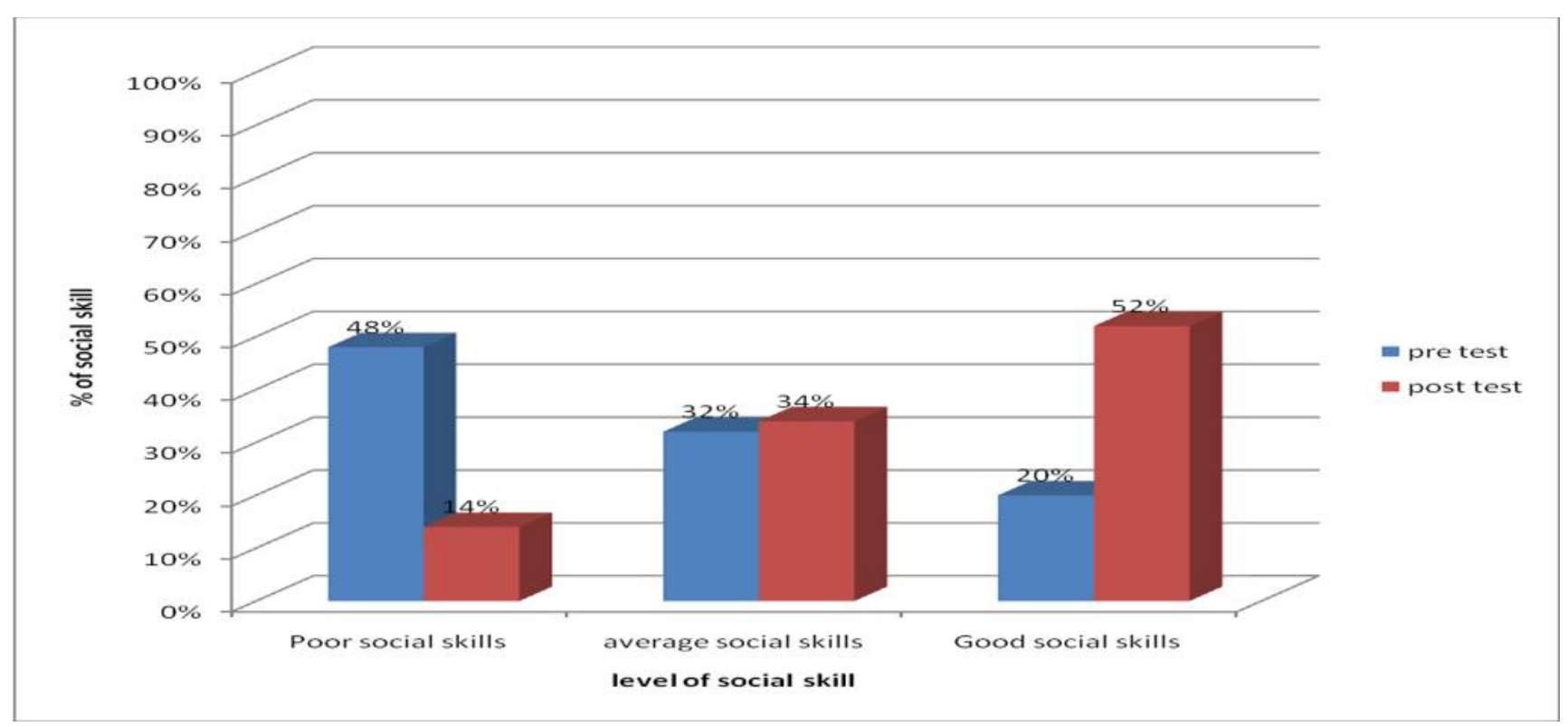

The above table shows that the level of social skill of students in the pretest was majority of them had poor social skill 24(48\%), average social skill $16(32 \%)$ and $10(20 \%)$ of them had good social skill. In the post test level $7(14 \%)$ of them had poor social skills and $17(34 \%)$ of the students had average social skills, $26(56 \%)$ of the students developed good social skills.

Table 2 Mean and standard deviation of pretest and posttest level of social skill among first year Baccalaureate Nursing students.

\begin{tabular}{|c|c|c|c|c|c|}
\hline \multirow{2}{*}{} & \multicolumn{2}{|c|}{ Pre test } & \multicolumn{2}{c|}{ Post test } & \multirow{2}{*}{ Paired " $t$ " value } \\
\cline { 2 - 5 } & Mean & S.D & Mean & S.D & \\
\hline Level of social skill & 6.58 & 2.37 & 17.96 & 2.912 & -3.4217 \\
\hline
\end{tabular}

$$
\mathrm{P}<0.01 * * \mathrm{~S}
$$

The above table indicates that in pretest the overall mean value of level of social skill was 6.58 with the SD of 2.37. In posttest the overall mean of social skill level was 17.9 with the SD 2.912. The paired' test value is -3.4217 .

\section{Conclusion}

The study concluded that there was a significant difference in the level of social skills of the students after social skill training. This revealed that good social skill training will help the students to interact socially and render quality care using of appropriate and effective social skills. And in order to acknowledge the reaction both from patients, their families, their relatives and other team members to receive and evaluate their messages correctly and to establish an effective communication with them, nurses who take charge in every part of the society must have the social skills ${ }^{2}$. 


\section{References}

1. Mariancollege.edu/blog/social-skills-nursingintrovert-shy/ (2015).Social Skills in Nursing Introversion and Shyness-Marian College of nursing.

2. Emine Senyuva, Hulya Kaya, Gonul Bodur (2014).Effect of social skills of nursing students of the project based teaching methods".393-398.

3. Lawrence E. Shapiro (2004) 101 ways to teach children social skills a ready-to-use, reproducible activity book, pg 16, 61, 78, 80, .25, 26, 29- 31
4. Arnold p. Goldstein et al (1980). Skill-streaming the adolescent. Champaign, Research press.

5. Emiko Yamamoto et al (2015) .Examination of a social skills training program related to transmitting and taking directions in basic nursing education". LIFE: International Journal of Health and Life-Sciences.Vol.1 Issue 1, pp. 227-237

6. http://grdspublishing.org/LIFE/life.html 227

\begin{tabular}{|c|c|}
\hline \multicolumn{2}{|c|}{ Access this Article in Online } \\
\hline \multirow{2}{*}{ 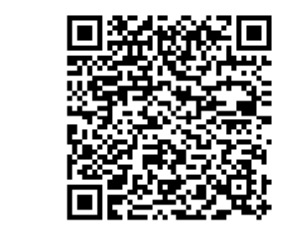 } & $\begin{array}{l}\text { Website: } \\
\text { www.ijarm.com }\end{array}$ \\
\hline & \multirow[t]{2}{*}{$\begin{array}{l}\text { Subject: } \\
\text { Nursing Science }\end{array}$} \\
\hline $\begin{array}{c}\text { Quick Response } \\
\text { Code }\end{array}$ & \\
\hline DOI:10.22192/ij & 2016.03 .10 .008 \\
\hline
\end{tabular}

How to cite this article:

J.Anitha and Dr C.Susila. (2016). Effectiveness of social skill training on social skills among first year Baccalaureate Nursing students. Int. J. Adv. Multidiscip. Res. 3(10): 78-81.

DOI: http://dx.doi.org/10.22192/ijamr.2016.03.10.008 